UCRL-JC-122875

PREPRINT

$$
\text { CONF- } 960477-.4
$$

\title{
Tank Leak Detection Using Electrical Resistance Methods
}

A. Ramirez

W. Daily

A. Binley

D. LaBrecque
MAY 151996

Q STII

This paper was prepared for submittal to the

Symposium on the Application of Geophysics to Engineering and Environment

Keystone, $\mathrm{CO}$

April 28-May 1, 1996

January 1996

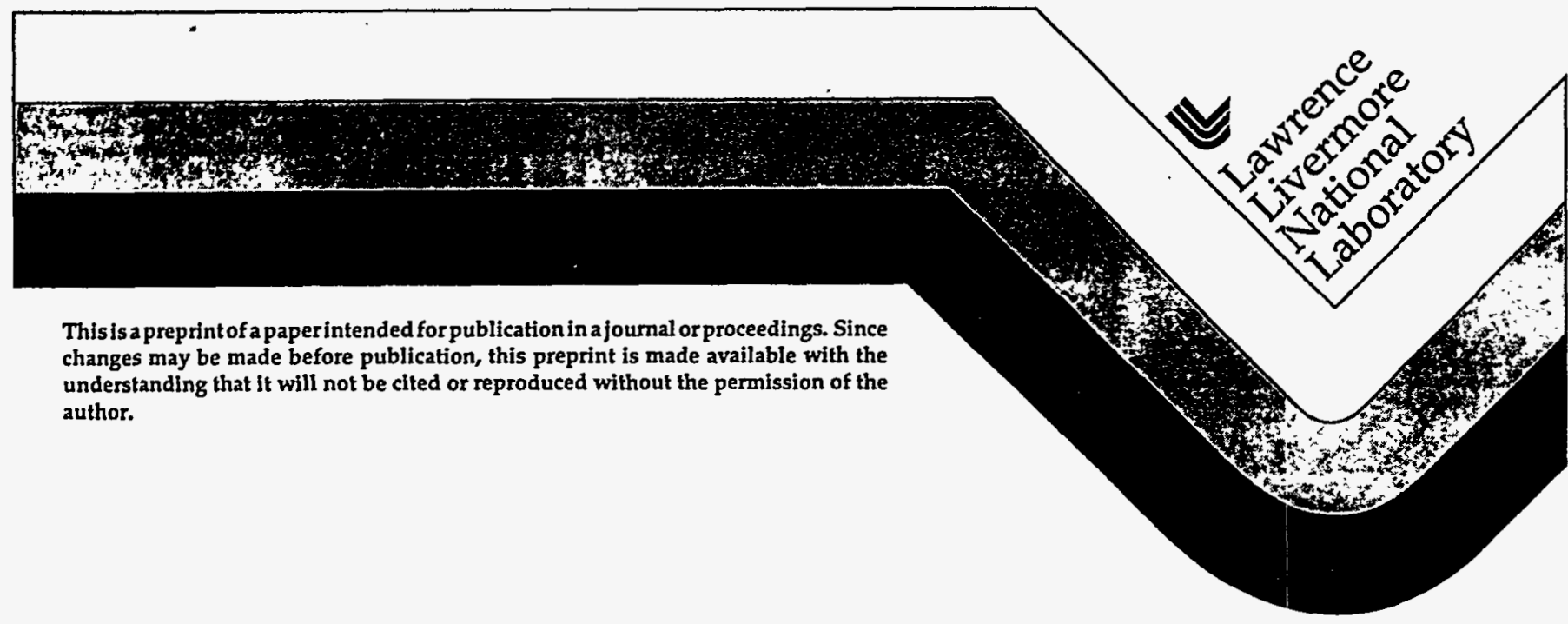

DISTAIBUTION OF THIS DOCUMENT IS UNLIMTEO 


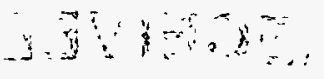

$\therefore$ ing $=0$

$\because \because \because \%$

\section{DISCLAIMER}

This document was prepared as an account of work sponsored by an agency of the United States Government. Neither the United States Government nor the University of California nor any of their employees, makes any warranty, express or implied, or assumes any legal liability or responsibility for the accuracy, completeness, or usefulness of any information, apparatus, product, or process disclosed, or represents that its use would not infringe privately owned rights. Reference herein to any specific commercial product, process, or service by trade name, trademark, manufacturer, or otherwise, does not necessarily constitute or imply its endorsement, recommendation, or favoring by the United States Government or the University of Califomia. The views and opinions of authors expressed herein do not necessarily state or reflect those of the United States Government or the University of California, and shall not be used for advertising or product endorsement purposes. 


\section{DISCLAAIMLRR}

Portions of this document may be illegible: in electronic image: products: Images are produced from: the best available original document: 
is the calculated transfer resistance for a-model of uniform resistivity. The transfer resistance is simply the ratio of voltage to current for an individual 4 electrode

resistivity structure which fits the data to some tolerance. The algorithm will tend to find resistivity models where there is minimal contrast between an element and its neighbors. It is necessary to modify the inversion algorithm because of the tank and soil. Otherwise, the resistivity associated with the tank will be "smeared" to the surrounding elements representing the soil and yield erroneous values. The algorithm used for this inversion was modified to allow for a non-smooth solution at the tank boundary.

The 3D reconstruction shown in Figure 3, is $21.3 \mathrm{~m}$ wide, $21.3 \mathrm{~m}$. long and $10.7 \mathrm{~m}$. tall and is the reconstructed volume bounded by the electrode arrays in the sixteen holes around the tank. Those parts of the reconstruction with resistivity differences between 0 and $-150 \mathrm{ohm}-\mathrm{m}$ are shown as transparent so that the interior of the block can be observed. Note that the 2D reconstructions in Figure 2 and 3D images in Figure 3 show the same approximate position, shape and size of the anomaly over time. The 3D images may provide a better view of the changes caused by the leak because: a) the flow regime is truly three-dimensional, so there is no need to assume that the resistivity extends to infinity in the third dimension, b) there is no need for interpolation between adjacent 2D slices, and, c) the effect of the metallic barrier is explicitly accounted for in the 3D images but not in the 2D images. However, the 3D images takes much longer to calculate ( 5 days per block) than the $2 \mathrm{D}$ images ( 20 minutes per plane).

Numerical modeling results suggest that the position of the anomaly has a significant effect on the results observed. Changes below the tank's center are observed with much less sensitivity than changes near the side of the tank. The modeling results suggest that anomalies closer to the electrodes are observed with greater sensitivity. If the tank itself is used as one large electrode, it may offer increased sensitivity and resolution because it is located closer to the leak point than any other electrode.

Figure 3 illustrates the effects of using the tank as an electrode. The figure compares two resistivity difference tomographs. The one on the left shows the results when only hole to hole data is used. The right image in Figure 3 shows the results when the tank is used in combination with the boreholes electrodes, i.e., hole to hole measurements and hole to tank measurements were used in combination. The difference image on the left of the figure is more elongated than the image on the right, which is more spherical. We do not have independent data that can be used to determine which of the two results is closer to the true structure. However, we speculate that the image on the right may more closely represent the true structure because the spherical shape is closer to what may be expected for a reasonably homogeneous sandy soil such as what exists at the experimental site.

The $3 \mathrm{~d}$ algorithm can also be used to model the effects of metal cased boreholes. Some of the metal tanks at the Hanford site are surrounded by metal cased vertical boreholes (Cruse et al., 1995). One approach considered in our work is to use these metal cased boreholes as long electrodes for ERT leak detection. The test site described in Section 2.2 and Figure 2 was modified to create an electrical analog to a tank surrounded by 4 metal cased boreholes and 4 normal ERT electrode boreholes. To approximate a metal cased borehole, the eight electrodes in an ERT borehole were shorted together, creating a piecewise continuous electrode between the top and bottom electrode. Every other ERT hole was used as a "metal casing analog". The data were inverted using the 3D resistivity algorithm and the "metal casing analogs" were modeled as vertical columns of highly conducting elements which extended from the ground surface to $10.7 \mathrm{~m}$ depth. 


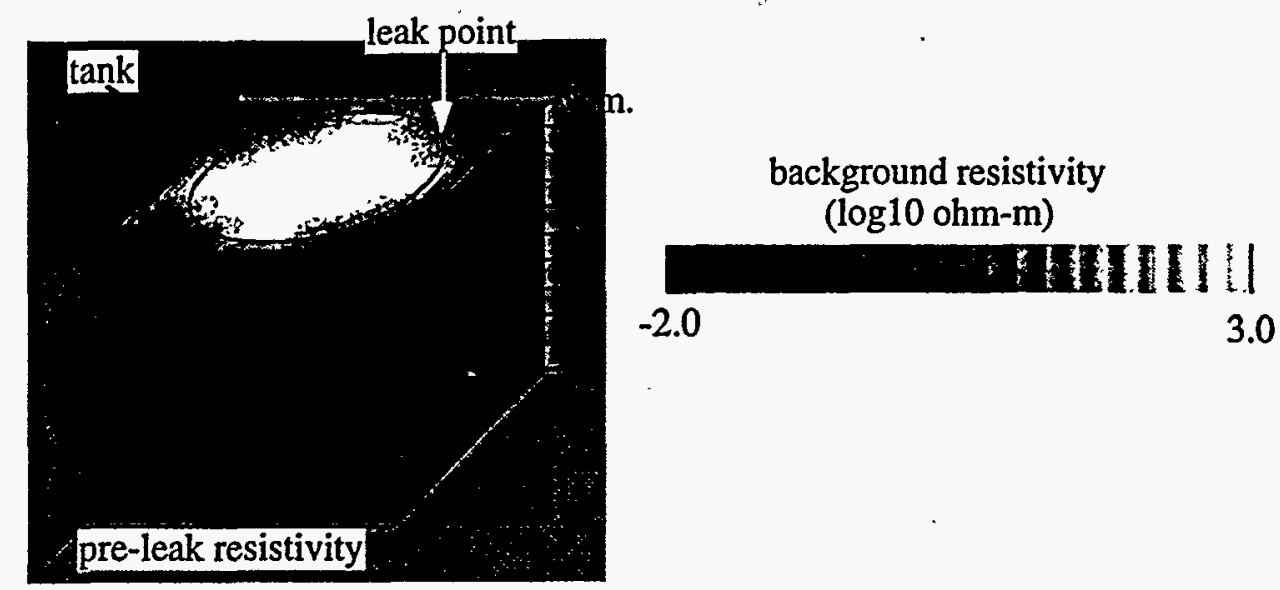

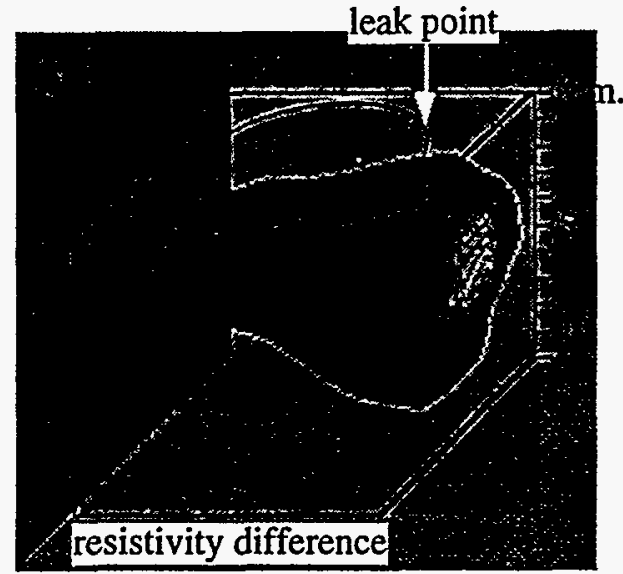

data from borehole electrodes only 3900 liters

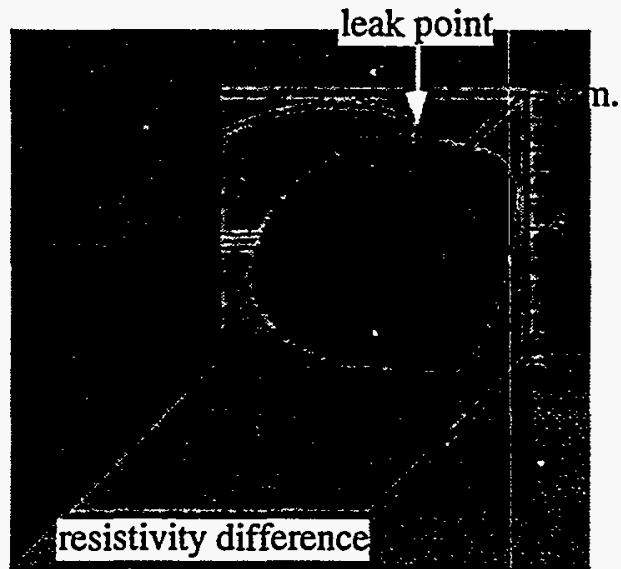

data from borehole and tank electrodes 3900 liters

\section{resistivity differences (ohm-m) \\ $-750.0$ \\ TIIIII:। \\ 0.0}

Figure 3 shows how the resistivity tomographs change when the tank is used as an electrode in combination with electrodes in the boreholes. The bottom two images show resistivity differences on the last day of the release; these images are transparent where the resisitivty differences observed were less than $150 \mathrm{ohm}-\mathrm{m}$. The data for the top left and bottom left images was collected using only the electrodes in the boreholes. The data for the right image was collected using the tank as an electrode as well as the borehole electrodes. 

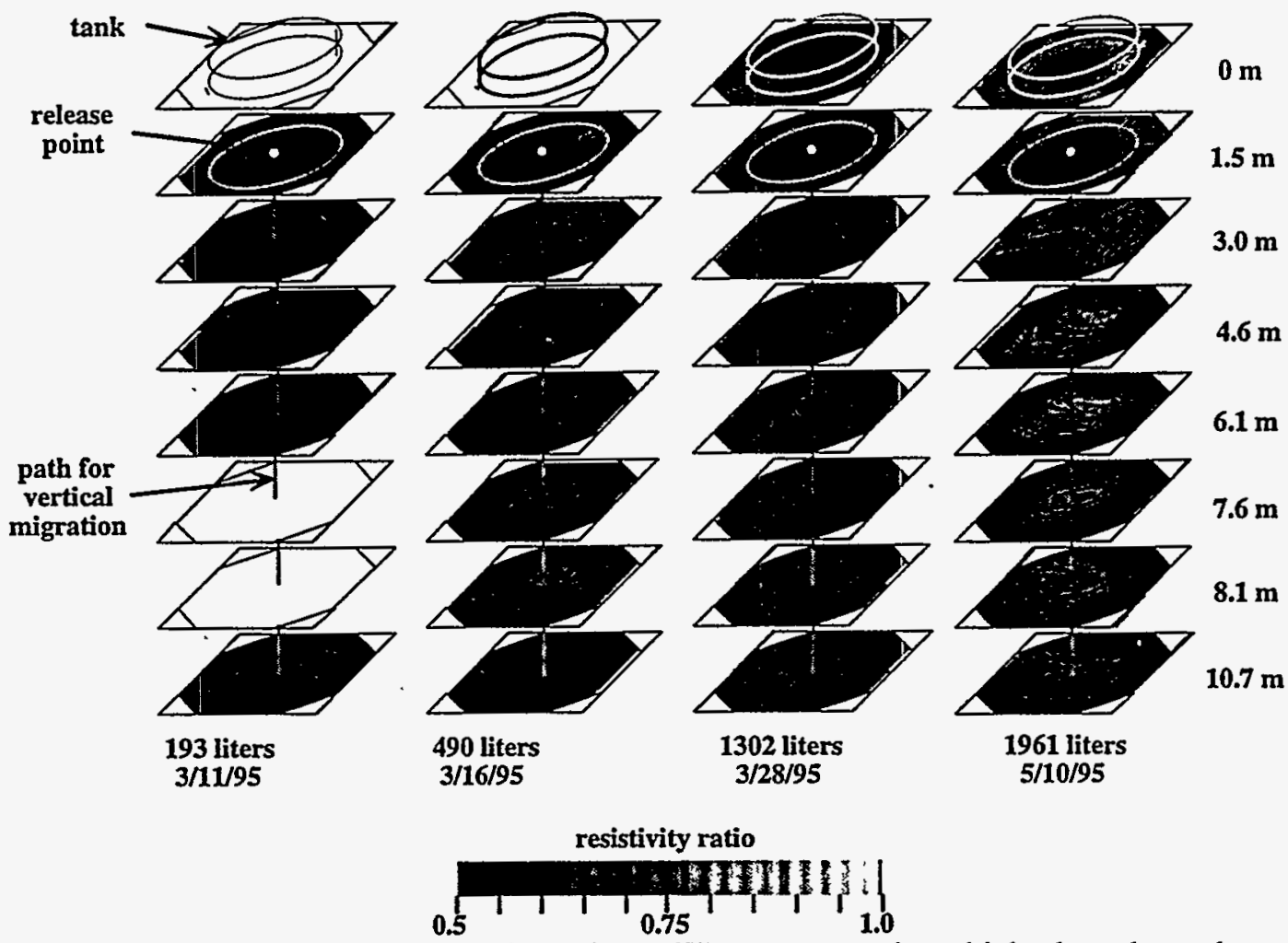

Figure 4 shows a series of two-dimensional ERT tomographs which show how the electrical resistivity of the soil decreased during the center release experiment. The range of values represented by the grey level used is identical used is identical to that used to depict the side release results in Figure 2. A vertical dotted line shows the trajectory the brine would follow if it moved straight down.

Ramirez et al., 1995, show resistivity differences obtained when four "metal casing analogs" along with four normal electrode boreholes (with eight electrodes in each borehole) were used during the center release. These results suggest that metal cased boreholes used as long electrodes, in combination with normal ERT electrodes, can be used to calculate reasonable images of resistivity changes caused by the leak.

Figure 4 presents two-dimensional (2D) tomographs collected during the course of the center release experiment (spill point location shown in Figure 2). Time and leaked volume increase from left to right on the figure. The images for March 11 show clearly detectable electrical conductivity increases below the release point and extending to the South and East. The changes observed increase in magnitude as time and spilled volume increase just as was observed during the side release. Also, note that the bottom of the changing region extends deeper as time increases. This behavior suggests that the brine is moving mainly down with some movement to the SE. The movement to the SE may be explained by the slight SE dip of the sand layers at the site.

The results obtained early during the middle release show that reliable changes associated with the leak were detected after 190 liters (50 gals.) had been released. These results are shown in Figure 4, left hand column of images. Note that data was not collected when 